$$
\text { for subrission: int. J. Climatology }
$$

\title{
Are stronger North-Atlantic southwesterlies the forcing to the late-winter warming in Europe?
}

J. Otterman'<terry@dao.gsfc.nasa.gov>, R. Atlas², S.-H. Chou ${ }^{2}$, J. C. Jusem ${ }^{3}$, R. A. Pielke, Sr. ${ }^{4}$, T.N. Chase ${ }^{3}$, J. Rogers ${ }^{6}$, G. L. Russell ${ }^{7}$, S. D. Schubert ${ }^{2}$, Y. C. Sud ${ }^{2}$, and J. Terry ${ }^{3}$

Key Words: climate trends, advancement of spring in Europe, ocean-to-land advection

\author{
Sweet and low, sweet and low, \\ Wind of the western sea, \\ Low, low, breathe and blow, \\ Wind of the western sea!
}

From The Princess, Alfred, Lord Tennyson

1. Land-Atmosphere-Ocean-Research; at Data Assimilation Office, Code 910.3,

NASA, Goddard Space Flight Center, Greenbelt, MD 20771, Tel.1(301) 286-1312.

2. Laboratory for Atmospheres, NASA, Goddard Space Flight Center, Greenbelt, MD 20771.

3. General Sciences Corporation, Beltsville, MD

4. University of Colorado, Boulder, $\mathrm{CO}$

5. Colorado State University, Fort Collins, $\mathrm{CO}$

6. Ohio State University, Columbus, $\mathrm{OH}$

7. NASA GISS, New York, NY

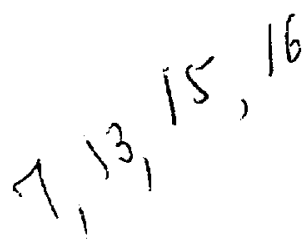




\section{Abstract}

We examine a possible mechanism leading to late-winter warming and thus to an early spring in Europe. From the NCEP Reanalysis, we extract for the years 1948-1999 oceansurface winds over the eastem North Atlantic, and air temperatures at the surface, $\mathrm{T}_{s}$, and at the $500 \mathrm{mb}$ level, $\mathrm{T}_{500}$, in late-winter and spring. $\mathrm{T}_{\mathrm{s}}$ is extracted at six European locations, all at $50.5^{\circ} \mathrm{N}$, ranging in longitude from $1.9^{\circ} \mathrm{E}$ (northeastern France) to $26.2^{\circ} \mathrm{E}$ (Ukraine). To quantify the advection of maritime air into Europe, we evaluate for 3pentad groups the Index $I_{n a}$ of the southwesterlies at $45^{\circ} \mathrm{N} ; 20^{\circ} \mathrm{W}: I_{n a}$ is the average wind speed at this point if the direction is from the quadrant $180^{\circ}-270^{\circ}$ (when the direction is different, the contribution counts as zero). In late winter correlations $\mathrm{C}_{\mathrm{it}}$ between the Index $I_{n a}$ and the temperature $T_{s}$ are substantial, up to the 0.6 level, in western Europe (but weaker correlations for Poland and Ukraine). $\mathrm{C}_{\mathrm{it}}$ drops sharply by mid- March, taking occasionally negative values subsequently. This drop in $\mathrm{C}_{\mathrm{it}}$ indicates that maritime air advection is no longer associated closely with the surface-air warming, the role of insolation becomes important, and thus the drop in $\mathrm{C}_{\mathrm{it}}$ marks the arrival of spring. Correlations $C_{i \Delta}$ between $I_{n: a}$ and our lapse-rate parameter $\Delta$, the difference between $T_{s}$ and $\mathrm{T}_{500}$, indicate that the flow of warm maritime-air from the North Atlantic into this "corridor" at $50.5^{\circ} \mathrm{N}$ is predominantly at low tropospheric level. By computing the best linear fit to $I_{n a}$ and $T_{s}$, the trends for the period 1948-1999 are evaluated. The trends are appreciable in the second- half of February and the first- half of March: in $I_{\mathrm{na}}$, the trends are 0.41 and $0.15 \mathrm{~ms}^{-1} /$ decade in pentad-groups $10-12$ and $13-15$, respectively $\left(I_{n a}\right.$ increased from 1948 to 1999 by 2.10 and $0.77 \mathrm{~ms}^{-1}$ ); in $\mathrm{T}_{\mathrm{s}}$ the trends for western 
Germany are 0.36 and $0.43^{\circ} \mathrm{C} /$ decade in these two pentad-groups $\left(\mathrm{T}_{\mathrm{s}}\right.$ in this location increased from 1948 to 1999 by 1.86 and $2.19^{\circ} \mathrm{C}$ ). Such higher near-surface temperatures would markedly influence sno: $\mathrm{N}$-melt and thus absorption of insolation by the surface. Our 3-pentad analysis points to the interval from mid-February to mid-March as the endof-winter period in which the southwesterlies over the eastern North Atlantic become stronger and the surface-air temperatures in Europe rise markedly, the lapse rate becomes steeper, and concurrently the longitudinal temperature gradient between the Somme (France) and the Oder (Germany/Poland border) $\left(-4.0\right.$ or $-4.5^{\circ} \mathrm{C}$ in 1948 for the $10^{\circ}$ longitude distance) is reduced by $0.8^{\circ} \mathrm{C}$, that is, by $20 \%$ of its 1948 value. Our thesis, that the observed late-winter warming and the corollary advancement of spring in Europe resulted at least in part from stronger southwesterlies over the North Atlantic, merits further investigations. 


\section{Introduction}

A thesis is presented here that the late-winter warming and the corollary advancement of spring observed toward the end of the $20^{\text {th }}$ century in mid-latitude Europe (see, for instance, Menzel and Fabian, 1999; Demarée et al., 2001; Jaagus and Ahas, 2000) may be, at least in part, due to increasing southwesterlies over the eastern North Atlantic: more frequent direction from the southwest, and higher speeds when the ocean-surface winds are from that direction.

Substantial correlations were found between the speed of the surface southwesterlies over the eastern North Atlantic and the February surface-air temperatures in France and in longitudinal strips through Europe, all the way to the foothills of the Urals (Otterman et al., 1999). The correlations for March were much lower. In a subsequent short study, pentad-by-pentad analysis showed a precipitous drop in these correlations for pentad 16 and higher (that is, Julian date 76, or March 16), when the correlations occasionally took negative values (Otterman et al., 2000). This drop in the correlations was interpreted as the switch in the control of the surface-air temperature in Europe, from the control in winter by the maritime-air advection, which raises surface-air temperatures when the ocean-surface winds are from the southwest, to that by the absorption of insolation in spring and summer. Indeed, it was suggested that the switch in the control can be regarded as most-relevantly defining the end of winter and the onset of spring.

In these studies from the Special Sensor Microwave Imager (SSM/I) and the ECMWF datasets, the analysis extended for the 11 -year period 1988-1998. In the present study we extract information about the surface winds over the eastern North Atlantic $\left(45^{\circ} \mathrm{N} ; 20^{\circ} \mathrm{W}\right)$ and the air temperatures at six European locations from the National Centers for 
Environmental Prediction (NCEP) Reanalysis (Kalnay et al., 1996), available now for the years 1948-2000. This much longer period of the available data allows us to assess trends. The correlation analysis for this period of 52 years presented here for several 3pentad groups indicates further that ocean-surface winds from the southwest constitute to a significantl degree the control of these temperatures in late winter.

\section{The NCEP Reanalysis.}

Our study is based on the NCEP Reanalysis dataset, described in detail by Kalnay et al. (1996), which extends from January 1948 essentially to the present. Improvements to the numerical weather prediction operational systems were introduced when satellite measurements become available (see Kalnay et al., 1996, for a documentation of the changes). The intent in processing was to produce a consistent dataset. Still, some discontinuity at high atmospheric levels apparently was introduced starting with 1979 , relative to the earlier (1948-1978) period when no satellite observations were available (Pawson and Fiorino, 1999; Pielke et al., 1998a, 1998b). This uncertainty, crucially important to the evaluation of trends, is addressed in a recent report on the Reanalysis project (Kistler et al., 2001). We discuss this question in the last section.

\section{The extracted data and computation of the correlations.}

From the NCEP Reanalysis we extract ocean-surface winds at $45^{\circ} \mathrm{N} ; 20^{\circ} \mathrm{W}$ (this location was chosen for computing $I_{\text {na }}$ since it provided higher correlation than 5 other locations, to the east, west, and south of $45^{\circ} \mathrm{N} ; 20^{\circ} \mathrm{W}$ ) for all available data-points ( 4 data-points per day), and compute for pentad- group ( 3 pentads) average the Index $\mathrm{I}_{\mathrm{na}}$ of southwesterlies: wind speed is counted toward the average only if the direction is from azimuth 180 to $270^{\circ}$ (if the direction is different, the point counts toward the average as a zero speed). 
Index $I_{n a}$ is plotted vs. the year of the Reanalysis, 1948-1999, for the pentad group 10-12 in Fig. 1 (solid black line). We note strong interannual variability: $I_{n a}$ has a zero value in the years $65,69,88$ and 93 , peaking at about $11 \mathrm{~ms}^{-1}$ in 90 and 97 . (Index computed in a "box" in the eastern North Atlantic for February of these two years was about $8 \mathrm{~ms}^{-1}$, see Otterman et al., 1999).

We likewise extract from the NCEP Reanalysis $2-\mathrm{m}$ temperature $\mathrm{T}_{\mathrm{s}}$ (and also $500 \mathrm{mb}$ level temperature $T_{500}$, see below, where we compute our lapse-rate parameter) at six European locations, all at $50.5^{\circ} \mathrm{N}$ : (1) northeastern France, $1.9^{\circ} \mathrm{E}$, (2) western Germany, $7.5^{\circ} \mathrm{E}$, (3) eastern Germany, $11.2^{\circ} \mathrm{E},(4)$ western Poland, $16.9^{\circ} \mathrm{E},(5)$ eastern Poland, $22.5^{\circ} \mathrm{E}$, and (6) Ukraine, $26.2^{\circ} \mathrm{E}$. Our motivation is to analyze how the influence of the maritime air advection on the temperatures $T_{s}$ [established for longitudinal strips through Europe by the Otterman et al. (1999)] changes with the distance from the North Atlantic. The six temperatures $T_{s}$ are plotted for the pentad-group 10-12 alongside $I_{n a}$ in Fig. 1. We note strong interannual variations, which generally tend to follow the variations in $I_{n a}$ presented there. For instance, we observe record or near-record temperatures $T_{S}$ in all six locations in the high-Index year 1990, and low $\mathrm{T}_{\mathrm{s}}$ in the zero-Index years 65 and (except for France) 88. (However, $T_{s}$ took very low values in 1963, when $I_{n a}$ was $5 \mathrm{~ms}^{-1}$ ). The best- fit to $T_{s}$ for eastern Germany, showing a substantial positive trend in the pentad group 10-12 for this 52-year period (dotted line in Fig. 1), is discussed later.

To point out how effective is the influence of the North-Atlantic southwesterlies in late winter over the onset of spring in Europe, we compare the Final-Snow-Dates, FSD, in the high- $\mathrm{I}_{\mathrm{na}}$ years vs. the average FSD in southern Estonia. For the two southernmost stations, Vöru and Valga, FSD dates were respectively March 19 and March 21 in 1950 
$\left(\mathrm{I}_{\mathrm{na}}\right.$ of $\left.8 \mathrm{~ms}^{-1}\right)$, and March 16 and 15 in $1990\left(\mathrm{I}_{\mathrm{na}}\right.$ of about $\left.11 \mathrm{~ms}^{-1}\right)$, as compared to the April 2 mean FSD: an advancement by about two weeks (personal communication by $\mathbf{J}$. Jaagus, University of Tartu).

Correlations $C_{i t}$ between $I_{n a}$ and the temperatures $T_{s}$, for pentad-groups from 7-9 to 28 30, are plotted as Fig. 2. We note close grouping of the 3 western locations (France, and two locations in Germany), and separately the 3 eastern locations (two locations in Poland, and one in Ukraine). For the three western station, $\mathrm{C}_{i \mathrm{t}}$ is in the 0.4 to 0.6 range in February and first- half of March, dropping sharply for pentad - group 16-18, that is, the second- half of March. Such a drop in the pentad- by- pentad correlation analysis was interpreted as marking the onset of spring in Europe (see Otterman et al., 2000): as the sun rises higher above the horizon and the snow-melt reduces the surface albedo, insolation replaces advection as the dominant control of the temperatures.

$\mathrm{C}_{\mathrm{it}}$ for the three eastern locations take lower values in late winter than those for the three western locations. We attribute this difference in the climate characterization by $\mathrm{C}_{\mathrm{it}}$ to the Sudeten Mountains and possibly to the higher North Carpathian Mountains and to the longer distance involved in the maritime- air advection. The drop in $\mathrm{C}_{\mathrm{it}}$ into spring for eastern these locations is more gradual.

$\wedge$

We observe in the maps of the surface winds when $I_{\text {na }}$ takes high value a southwesterly flow from the North-Atlantic, with the direction often rotating anticlockwise by some $20^{\circ}$ over the continent. Except for the mountains mentioned above os

D the seuth of the corridor), which apparently (see the reduction in $C_{i t}$ for the 3 locations to the east) Constitute to some extent a barrier to the near-surface flow the advection of the i warm maritime air in the "corridor" from the North Atlantic into Ukraine at $50.5^{\circ} \mathrm{N}$ takes 
place at low tropospheric levels. Thus the primary effect is that air temperatures $T_{\mathrm{s}}$ at 2$\mathrm{m}$ level are raised, and the lapse rate is enhanced by this advection. This low- level flow is indicated by the positive correlations $C_{i \Delta}$ between $I_{n a}$ and the lapse-rate parameter $\Delta$, which is the difference $T_{i s}-T_{500}$. Correlations $C_{i \Delta}$ (not presented here) are smaller than $\mathrm{C}_{\mathrm{it}}$, taking in the pentad-groups 7-9 and 10-12 the value up to 0.3 for the 3 western locations and up to 0.2 for the eastern locations. Again, (as in Fig. 2), fairly close grouping of $\mathrm{C}_{\mathrm{i} \Delta}$ characterize the 3 western locations, and separately the 3 eastern locations. These groupings point out to our correlations $\left(C_{i t}\right.$ as well as $\left.C_{i \Delta}\right)$ as of value in delineating homogeneous climatic regions.

We selected for our analysis 3 - pentad groups as the time- units, after finding that this approach produced more consistently substantial correlations when compared to the onepentad analysis. This can be well understood since the maritime airmasses take quite a few days (note in Fig. 1 the variability of the wind speed) to arrive at the six European locations, which are distant from the North Atlantic point $20^{\circ} \mathrm{W}$ (where we compute $\mathrm{I}_{\mathrm{na}}$ ) by up to $46^{\circ}$ in longitude (in the case of Ukraine). Longer time-units are counterindicated, since periods of differing teleconnections, different seasons or subseasons, would be combined in one time-frame. A study based on division of the year into 4 seasons, customary in climate studies (see for instance, Ross et al., 1996) or even into 8 seasons (such as in a study by Jaagus and Ahas, 2000) would have failed to appropriately quantify (or even detect) trends reported here.

\section{Evaluation of trends and the 1948-to-1999 changes}

We evaluate trends in the extracted data, $I_{n a}$ and $T_{s}$, regression analysis of these seven 
variables for four time periods. The best fit to $T_{s}$ in northeastern Germany, $11.2^{\circ} \mathrm{E}$, for the pentad-group 10-12 is shown in Fig. 1, where we easily note that the slope (the trend) is small when compared with that of interannual variations. The trends for pentadgroups 7-9 to $16-18$, presented in Table 1 , are consistent (positive) and appreciable for $I_{\text {na }}$ and all locations in Europe for only two pentad-groups, 10-12 (second half of February) and 13-15 (first half of March). The resulting changes for the 52-year period are fairly appreciable for these two pentad-groups: from 1948 to 1999 the Index increased by 2.10 and $0.77 \mathrm{~ms}^{-1}$, respectively, while the corresponding increases of $T_{s}$ in western Germany were 1.9 and $2.2^{\circ} \mathrm{C}$. In other locations the temperature increases are likewise reported for this 30-day period important for the timing of final snow-melt in Europe, but they are smaller. All these 1948-1999 changes are smaller than the standard deviations from the best fit lines (Table 1), indicating that our thesis is not based on robust statistics. In the 3 pentad group preceeding the mid-February to mid-March period, as well as in the subsequent group (which we regard as already spring), we report small negative trends in $\mathrm{T}_{\mathrm{s}}$ (with one exception); the trends in $\mathrm{I}_{\mathrm{na}}$ are also small.

In view of the correlations between $I_{n a}$ and the lapse rate parameter $\Delta$, the increases in $I_{n a}$ in the mid-February to mid.-March period must have produced a steeper lapse rate, appreciably so in the 3 western locations, only weakly in the east. $T_{s}$ in eastern Germany increased by $0.8^{\circ} \mathrm{C}$ more than in northeastern France (Table 1). Thus, the longitudinal temperature gradient between the Somme and the Oder $\left(-4.0\right.$ or $-4.5^{\circ} \mathrm{C}$ in 1948 for the $10^{\circ}$ longitude distance) is reduced by $0.8^{\circ} \mathrm{C}$, that is, by $20 \%$ of its 1948 value.

\section{Discussion and conclusions}

Late-winter warming over the recent decades and the corollary advancement of spring in 
Europe at latitudes $54-60^{\circ} \mathrm{N}$ can be regarded as established trends, evidenced the surfaceair temperature analysis in Belgium by Demerée et al. (2001), and by an analysis of phenulogical events for most of Europe by Menzel and Fabian (1999) and for Estonia by Jaagus and Ahas (2000). This trend is consistent with the rising late-winter temperatures in the $1948-1999$ period in the six locations at $50.5^{\circ} \mathrm{N}$, from France to Ukraine, reported here from the NCEP Reanalysis.

Menzel and Fabian (1999) put the warming trend which they report (averaged for . Europe) in the framework of the global warming, even though a cooling in the Balkans is reported. Indeed, regional cooling has been reported in simulation of the global warming (Russell and Rind, 1999). Nevertheless, the Balkans cooling suggests that causes specific to the warming in mid-latitude Europe should be examined.

Hurrell (1996) associated the surface warming over the Northern Hemisphere since the mid-1970's with changes in the Southern Oscillation, the North Atlantic Oscillation, and circulation over the North Pacific. Hurrell and Trenberth (1996) suggested that tropospheric depth-averaged temperature (specifically, the MSU-derived temperatures in their study) are primarily forced by advection. They point out that surface temperature variability is dominated by processes controlling surface fluxes and heat storage. Highly pertinent to our thesis is the remark by Plag and Tsimplis (1999): "Even small fluctuations of the global circulation pattern on interannual to decadal time scales may induce significant changes in range and form of the seasonal cycle in a region." Rogers (1997) associated climate variability of North Europe with the storm track variations over the North Atlantic. Our study follows the concepts presented in the above references. Advection from the warm ocean surface constitutes apparently the control of the surface- 
air in Europe in late winter (Otterman et al., 1999), as we further analyze for the 3pentad groups here. A thesis is presented that this trend to earlier onset of spring may be, at least in part, due to more dominant southwesterlies over the eastern North Atlantic. Our 3-pentad analysis points to the interval from mid-February to mid-March as the endof-winter period, in which the surface-air temperatures in Europe rose appreciably, and concurrently the southwesterlies over the eastern North Atlantic became considerably stronger. We envisage warm (and moist) low-level advection directly increasing the surface-air temperature (anyway, in a layer below $700 \mathrm{mb}$ ), and at the same time enhancing the lapse rate. This flow induces strong upward vertical motion at $700 \mathrm{mb}$ level, which we observe subsequent to days with strong southwesterlies (speeds above 20 $\mathrm{ms}^{-1}$ ). In these vertical motions water vapor moves to higher (cooler) levels, clouds form, which reduces the loss of heat to space (it is immaterial in this respect whether precipitation is produced or not).

We compared surface-air temperature measured in Brussels (average of daily maximum and minimum temperatures) with the Reanalysis data in northeastern France. These two locations are not very far from each other, and thus the temperature differences are rather small. Root-mean square differences are 1.48 and $1.91^{\circ} \mathrm{C}$ for pentad-group $10-12$ and 13-15 respectively in the years 1948-1973 (first-half of the Reanalysis), and 0.90 and $0.93^{\circ} \mathrm{C}$ for the $1974-1999$ period, between which a discontinuity might have been introduced. The difference between the two periods, of $\sim 0.5^{\circ} \mathrm{C}$, in these France-toBelgium differences is likely to be the result of stronger winds in the 1974-1999 period, which reduced the temperature gradients. This calculation suggests that if the NCEP 
Reanalysis does have a discontinuity, it is not very large in the case of the near-surface data: most of the 1948-1999 temperature differences in these two pentad-groups (Table 1) are larger than $0.5^{\circ} \mathrm{C}$.

The very strong interannual variablity in $I_{n a}$ and temperature $T_{s}$ can be considered as noise in our study of trends. Thus, the pronounced increases in the 2-m temperatures from 1948-to-1999 for a fraction of the Hemisphere and for the short-time period of 30 days (mid-February to mid-March) are not established by high-significance statistics. The possibility that in the NCEP Reanalysis a discontinuity was introduced when satellite-derived information was incorporated raises an uncertainty as discussed in the summary report on the project (Kistler et al., 2001): "during the earliest decade (19481957, there were fewer upper air data observations and they were made 3 hours later than the current main synoptic times, ... so the Reanalysis is less reliable than for the later 40 years". It is unlikely that this caveat applies forcefully in the case of the ocean-surface winds, for which ample information was available for the entire period 1948-1999 (from the ship reports over the North Atlantic). The caveat does apply to the temperatures $T_{s}$ and $\mathrm{T}_{500}$, which were not utilized in producing the Reanalysis.

The increase in $I_{\text {na }}$ derived here from the NCEP Reanalysis is consistent with several previous studies, which reported an increase in the wave height over the North Atlantic, resulting from the trend to stronger winds (Carter and Draper, 1988; Bacon and Carter, 1991; Kushnir et al., 1997; Gulev and Hasse, 1999). Specifically, trends in the southwesterlies have not been analyzed. Pressure gradients are the underlying mechanism (Bacon and Carter, 1993), which are affected by sea-surface temperature (SST). The enhancement of the North Atlantic southwesterlies may stem from changes 
in SST, such as the increasing temperature gradients between $45^{\circ} \mathrm{N} ; 20^{\circ} \mathrm{W}$ and $35^{\circ} \mathrm{N}$; $35^{\circ} \mathrm{W}$ which we observe (but do not discuss here). The increased melting of the Greenland ice sheet (Abaalati and Steffen, 1996) and the higher frequency of icebergs breaking off the Greenland shores (NOAA, 1999), by cooling the waters of the northwestern North Atlantic, might have affected the pattern of the ocean currents and produced this SST trend.

The thesis presented here closely parallels the report that the winter warming in the Czech Republic is due in part to changes in the circulation patterns in this country (Huth, 2001). We envisage that changes in the circulation over the European continent are forced by changes in the surface winds over the North Atlantic, which are quantified by a specific Index, $\mathrm{I}_{\mathrm{na}}$. These circulation patterns are in a large measure influenced by the North Atlantic Oscillation. However, $I_{n a}$ apparently is a more directly relevant parameter for characterizing maritime-air advection into Europe in winter (see Otterman et al., 1999, for detailed discussion). Because of its importance, our concept merits further examination.

Acknowledgements: We thank G. Demarée, Royal Meteorological Institute of Belgium, for the meteorological data from the Brussels station. Comments by J. Angell, NOAA, and J. Jaagus, University of Tartu, and R. Huth, Institute of Atmospheric Physics, Prague, significantly improved the presentation of our thesis.

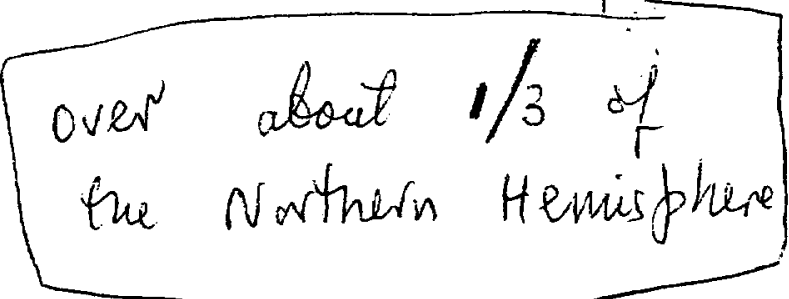




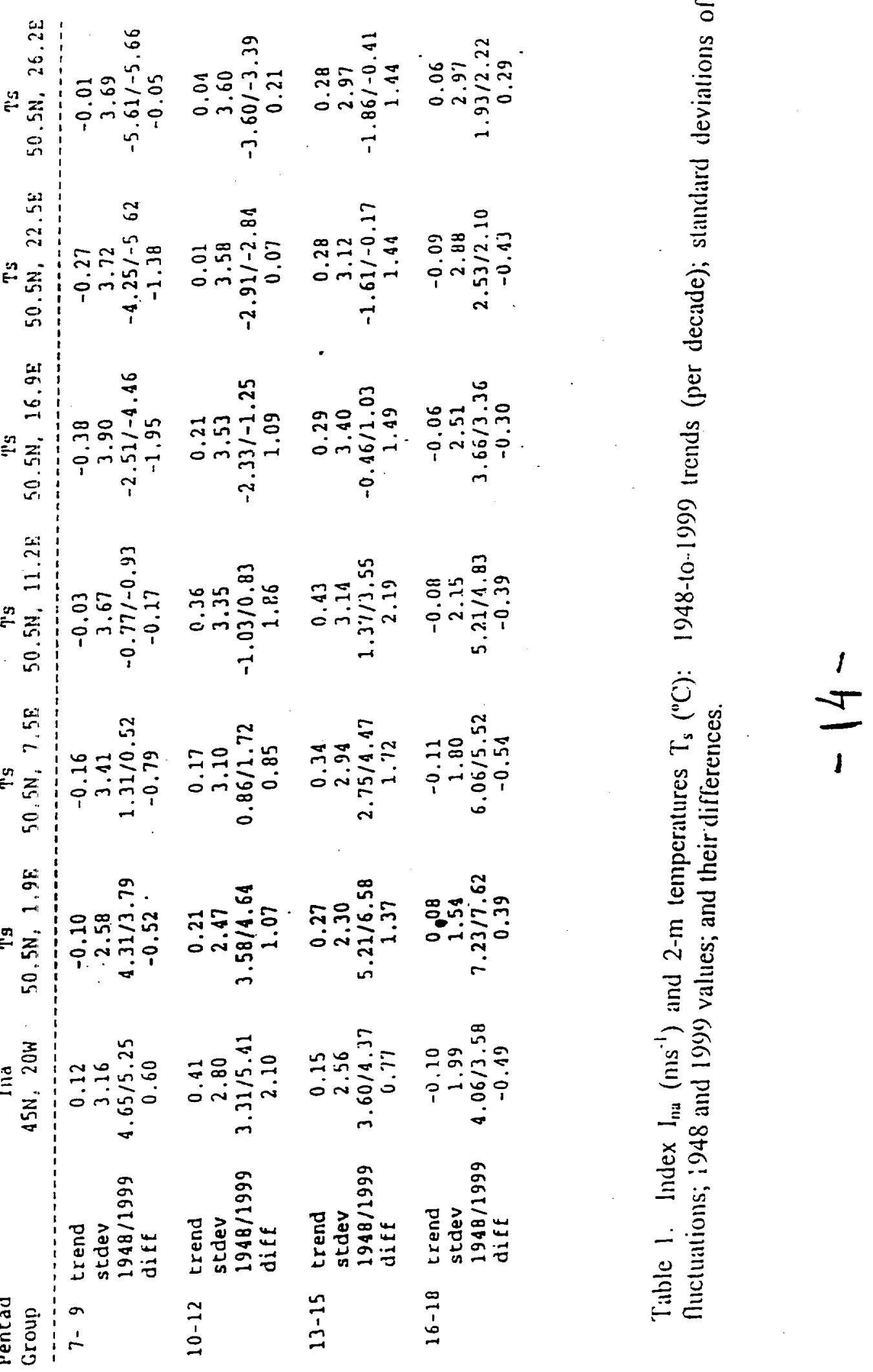




\section{References}

Abdalati, W. and K. Steffan, 1996. Snowmelt on the Greenland ice sheet as derived from passive microwave satellite data, $J$. of Climate, 10, 165-175.

Bacon, S., and D. J. T. Carter, 1991. Wave climate changes in the North Atlantic and North Sea, Int. J. Climatol., 11, 545-558.

Bacon, S., and D. J. T. Carter, 1993. A connection between mean wave height and atmospheric pressure gradient in the North Atlantic, Int. J. Climatol., 13, 423-436.

Carter, D. J. T., and L. Draper, 1988. Has the northeast Atlantic become rougher? Nature, 332, 494.

Demarée, G., P.-J. Lachaert, T. Verhoeve and E. Thoen, 2001. The long-term daily Central Belgium Temperature (CBT) time-series 1767-2000. History of the Instrumental Meteorological Observations in Belgium, invited paper, Special Issue, Climatic Change.

Gulev, S. K., and L. Hasse, 1999. Changes of wind waves in the North Atlantic over the last 30 years, Int. J. Climatol., 19, 1091-1117.

Hurrell, J. W., 1996. Influence of variations in extratropical wintertime teleconnections in Northern Hemisphere temperature, Geophys. Res. Lett., 23, 665-668.

Hurrell, J. W., and K. E. Trenberth, 1996. Satellite versus surface estimates of air temperature since 1979, J. Clim., 9, 2,222-2,232.

Huth, R. , 2001. Disaggregating climatic trends by classification of circulation patterns, Int. J. Climatol., 21, 12-13

Jaagus, J., and R. Ahas, 2000. Space-time variations of climate seasons and their correlation with the phenological development of nature in Estonia, Clim. Res. 15, 207-219.

Kalnay, E., et al., 1996.The NCEP/NCAR 40-year reanalysis project, Bull. Amer. Meteorol. Soc., 77, 437-471.

Kistler, R., E. Kalnay, W. Collins, S. Saha, G. White, J. Wollen, M. Chelliah, W. Ebisuzaki, M. Kanumitsu, V. Kousky, Huug van den Dool, R. Jenne, and M. Fiorino, 2001. The NCEP/NCAR 50-year Reanalysis: Monthly-means CD-ROM and Documentation, Bull. Amer. Meteor. Soc., 82, 247 -

Kushnir, y., V. J. Cardone, J. G. Greenwood, and M. A. Cane, 1997. The recent increase in North Atlantic wave heights, J. Climatol., 10, 2107-2113. 
Menzel, A., and P. Fabian, 1999. Growing season extended in Europe, Nature, 397, 65.

NOAA, 1999. National Snow and Ice Data Center Ice Patrol, iceberg sightings data base.

Otterman, J., R. Atlas, J. Ardizzone, D. Starr, J. C. Jusem, and J. Terry, 1999.

Relationship of late-winter temperatures in Europe to North Atlantic surface winds:

A correlation analysis, Theor. and Appl. Climatol., 64, 201-211.

Otterman, J., J. Ardizzone, R. Atlas, H. Hu, J. C. Jusem, D. Starr, 2000. Winter-to-spring transition in Europe $48-54^{\circ} \mathrm{N}$ : from temperature control by advection to control by insolation, Geophys. R.es. Lett., 17, 561-564.

Pawson, S., and M. Fiorino, 1999. A comparison of reanalyses in the tropical stratosphere Part 3: inclusion of the pre-satellite data era, Climate Dynamics 15, 241-250.

Pielke, Sr., R. A., J. Eastman, T. N. Chase, J. Knaff, and T. G. F. Kittel, 1973-1996 trends in depth-averaged tropospheric temperature, Jour. Geo. Res., 103, 16-927-16,933, 1998a.

Pielke, Sr., R. A., et al., Correction to "1973-1996 trends in depth-averaged tropospheric temperature," Jour. Geo. Res., 103, 28,909-28,911, 1998b.

Plag, H.-P. and M. N. Tsimplis, 1999.Temporal variability of the seasonal sea level cycle in the North Sea and Baltic Sea in relation to climate variability, Global and Planetary Change, 20, 173-203.

Rogers J., 1997. North Atlantic storm tract variability and its association to the North Atlantic oscillation and climate variability of Northern Europe, J. Climate, 10, 1635-1647.

Ross; R. J., J. Otterman, D. O. Starr, W. P. Elliott, J. K. Angell and J. Susskind, 1996. Regional trends of surface and tropospheric temperature and evening-morning temperature difference in northern latitudes, Geophys. Res. Lett., 23, 3179-3193.

Russell, G. L., and D. Rind, 1999. Response to $\mathrm{CO}_{2}$ transient increase in the GISS coupled model: regional coolings in a warming climate, J. Climate, 12, 531-539. 


\section{Figure Captions}

1. Surface-air temperature $T_{s}$ at six European locations, and the Index $I_{n a}$ of the southwesterlies at $45^{\circ} \mathrm{N} ; 20^{\circ} \mathrm{W}$, vs. the year of the Reanalysis, for pentad-group 10 12; trend (linear best fit) is indicated by dotted lines for eastern Germany, $11.2^{\circ} \mathrm{E}$, only.

2. Correlations $C_{i t}$ between $I_{n a}$ and the temperature $T_{s}$ at six European locations for eight pentad-groups, from 7-9 to 28-30. 


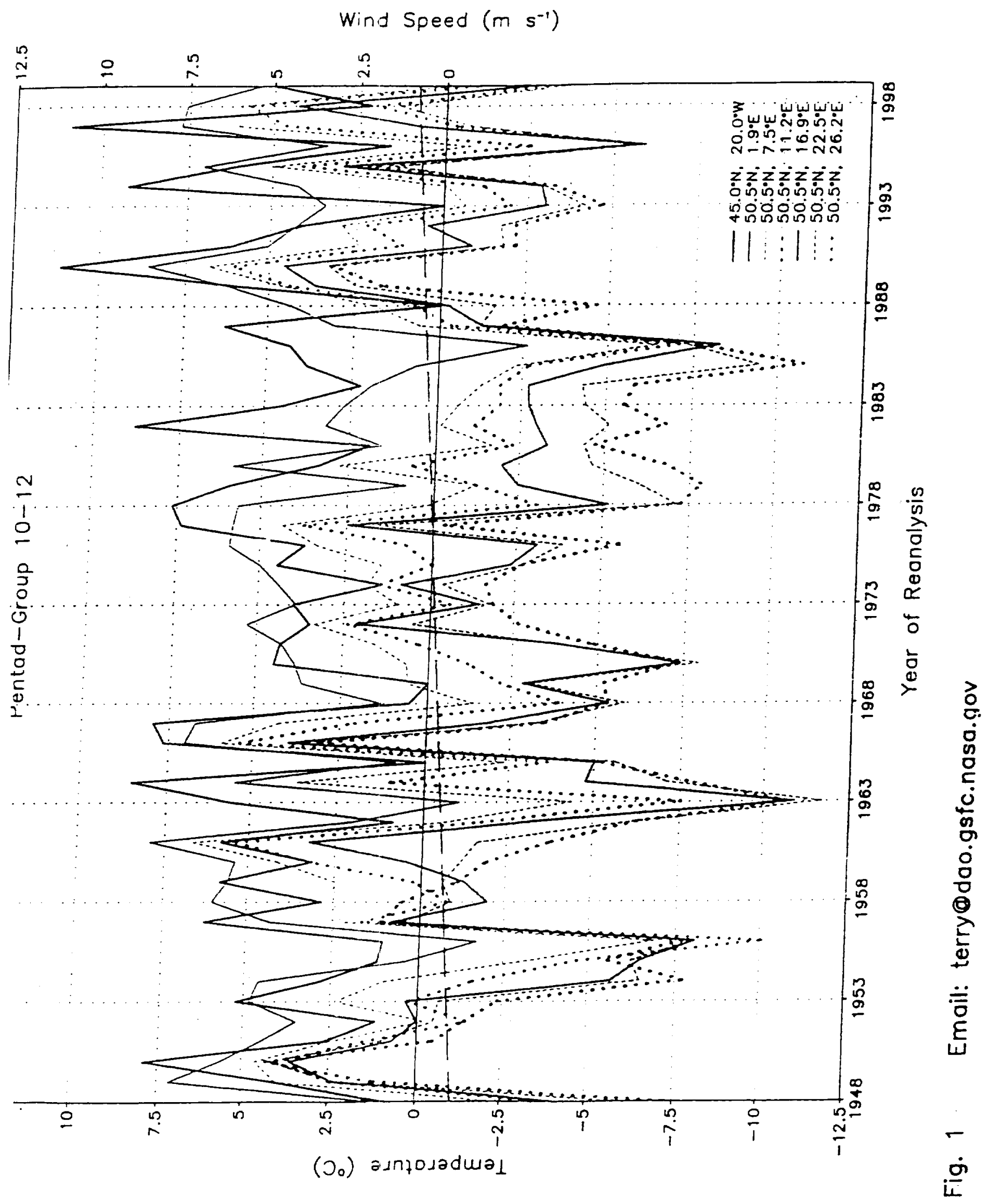




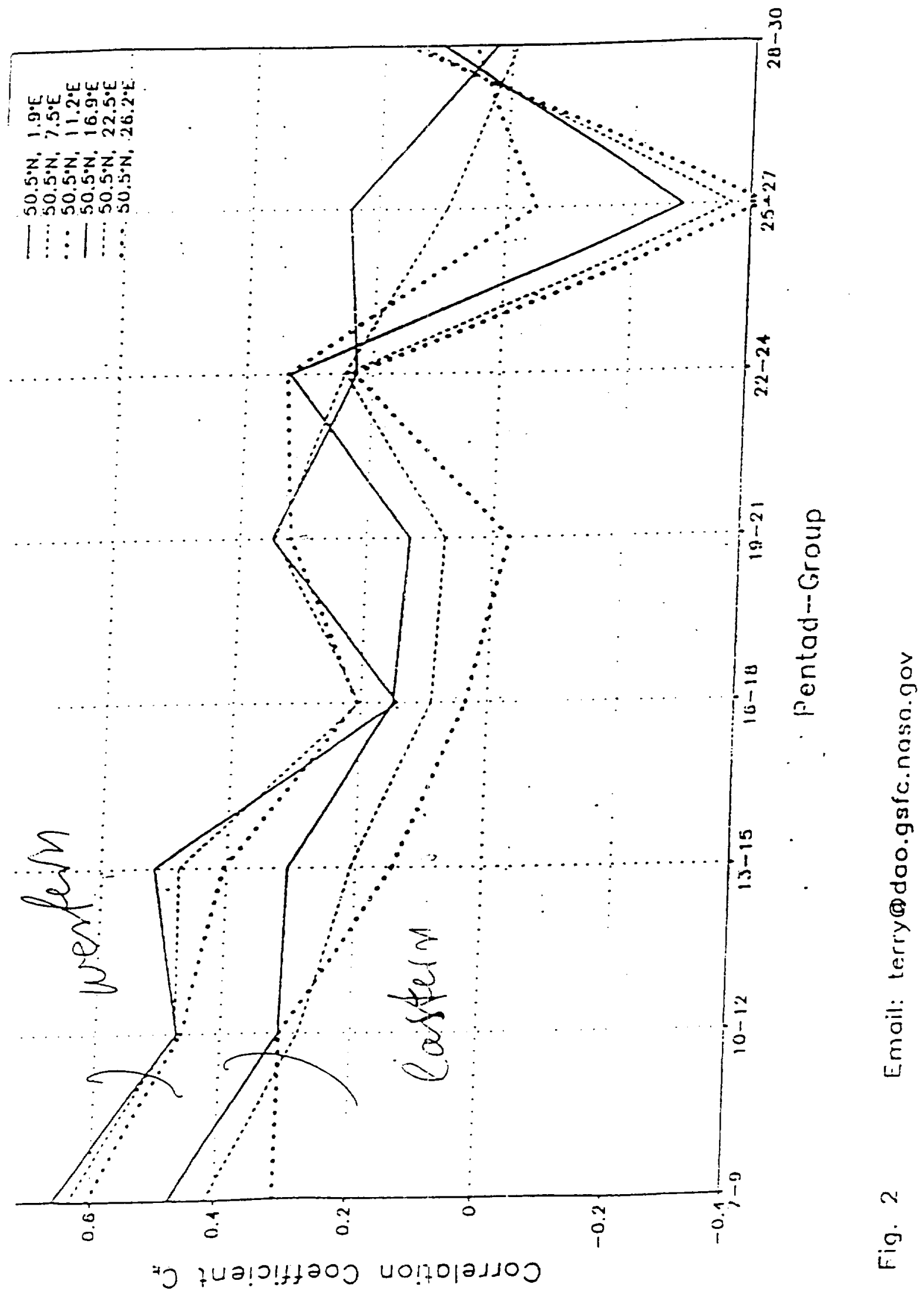

